\title{
DEVELOPMENT AND INTEGRATION OF A SCALABLE LOW NOx COMBUSTION CHAMBER FOR A HYDROGEN-FUELED AEROGAS TURBINE
}

\section{S. Boerner ${ }^{1}$, H. H.-W. Funke ${ }^{1}$, P. Hendrick ${ }^{2}$, E. Recker ${ }^{3}$, and R. Elsing ${ }^{4}$}

\author{
${ }^{1}$ Aachen University of Applied Sciences \\ 6 Hohenstaufenallee, Aachen 50264, Germany \\ ${ }^{2}$ Université Libre de Bruxelles \\ 50 Av. F. D. Roosevelt, Brussels 1050, Belgium \\ ${ }^{3}$ Royal Military Academy \\ 30 Av. de la Renaissance, Brussels 1000, Belgium \\ ${ }^{4}$ Diehl Aerospace GmbH \\ 23 Alte Nußdorfer Strasse, Überlingen 88642, Germany
}

\begin{abstract}
The usage of alternative fuels in aircraft industry plays an important role of current aero engine research and development processes. The micromix burning principle allows a secure and low NOx combustion of gaseous hydrogen. The combustion principle is based on the fluid phenomenon of jet in cross flow and achieves a significant lowering in NOx formation by using multiple miniaturized flames. The paper highlights the development and the integration of a combustion chamber, based on the micromix combustion principle, into an Auxiliary Power Unit (APU) GTCP 36-300 with regard to the necessary modifications on the gas turbine and on the engine controller.
\end{abstract}

\section{INTRODUCTION}

The finite nature of fossil fuel supply impacts future aircraft development processes. Gas turbines due to their advantages as reliable, efficient, light-weight and long-life propulsion systems will play a decisive role in this process. At long sight, hydrogen as energy carrier, produced by wind or solar energy, can introduce the aspect of renewable energy into gas turbine operation and substitute fossil energy.

For the operation of a hydrogen-fueled gas turbine, two major modifications on the system gas turbine are necessary. The utilized combustion technology has to be modified to guarantee efficient, stable, and low NOx hydrogen combustion

This is an Open Access article distributed under the terms of the Creative Commons Attribution License 2.0, which permits unrestricted use, distribution, and reproduction in any medium, provided the original work is properly cited. 
under variable operational conditions. Besides combustion technology modifications, the gas turbine's control and metering unit system has to be adapted to guarantee safe, rapid, and precise changes of the engine power level as demanded by aircraft operation [1].

Since years, the research activities at Aachen University of Applied Sciences are focused on investigating these two aspects. To enable safe and low NOx hydrogen combustion, the micromix burning principle has been developed based on the fluid physical phenomenon of jet in cross flow [2]. By using multiple miniaturized diffusion type flames injected across the entire main flow area to as many injection points as possible, the combustion principle achieves a significant reduction of the NOx emissions.

In order to demonstrate low NOx hydrogen operation, a kerosene-driven gas turbine is modified into a hydrogen-fueled one. As far as possible, the operational characteristic of the hydrogen gas turbine should be similar to the kerosene-fueled engine. For achieving low NOx operation of the hydrogen-fueled aeroengine, a combustion chamber based on the micromix burning principle is built for the integration into the gas turbine.

The transition from kerosene to hydrogen, from a liquid to gaseous fuel, has an important impact on the chosen control and fuel metering strategy of the gas turbine. Additionally, for the setting of the control laws and parameters, the characteristic of the combustion chamber has to be regarded in order to guarantee secure low NOx operation of the hydrogen-fueled gas turbine.

\section{AUXILIARY POWER UNIT GTCP 36-300}

For the modification, an APU GTCP 36-300 (Fig. 1) is used. To compare the influence of the changeovers for the hydrogen application on engine's behavior

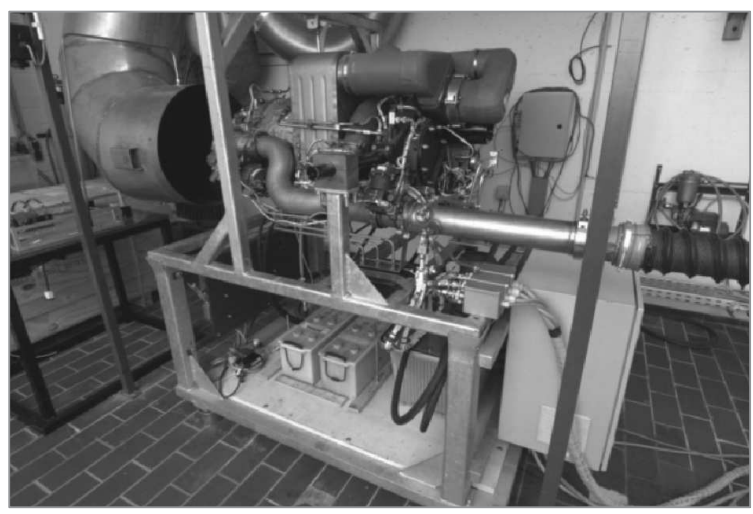

Figure 1 Auxiliary power unit GTPC 36-300 in test rig 
and on the exhaust gas emissions, two APU are available for the experimental work. While one APU has been modified for hydrogen operation, the other was intended as kerosene reference system. Via an extra load compressor and an electric generator, the GTCP 36-300 provides pneumatic and electric power to aircrafts. The single-stage radial compressor, the annular combustion chamber consisting of 6 single fuel nozzles, and the single-stage radial turbine are the main components of this single shaft engine. The gas turbine can produce up to $335 \mathrm{~kW}$ and is controlled by the Versatile Engine Control Box (VECB), built by Diehl Aerospace GmbH.

\section{MICROMIX BURNING PRINCIPLE}

The operation of a hydrogen-fueled gas turbine with nonoptimized combustors for hydrogen application results in high NOx emissions [1]. With regard to the reduction of the environmental impact and the compliance with legal standards, the applied combustion technology has to be optimized in order to achieve a lowering of the NOx formation during the combustion process. The formation routes of NOx formation and their influencing parameters, especially during hydrogen operation, is part of several current research efforts. In [3], the different routes are summarized and intensively reviewed. Lefebvre highlights in [4] reaction rate, mixture, and residence time as the three major parameters influencing the formation of the NOx emissions. The reaction rate is a dimension for the temperature and pressure conditions, prevailing during the gas turbine's combustion process. The parameter results from the chosen cycle conditions of the gas turbine. An optimization of this parameter with regard to lowering the $\mathrm{NOx}$ formation is accompanied with a decrease of efficiency of the gas turbine. The enhancement of the grade of mixedness, up to premixed conditions, is another common way to decrease the NOx formation [5]. However, especially under gas turbine's operational conditions, the potential risk of flash back is existent. The usage of diffusive type flames requires optimized mixture capabilities to limit higher formation rates. The residence time of the reactants in the hot region of the flame is the last remaining parameter influencing the formation process. Increased residence times result in higher NOx emissions [6].

To enhance the mixing, the micromix burning uses the fluid phenomenon of jet in cross flow. The hydrogen is injected vertical into the airstream. After mixture of reactants, the hydrogen burns in diffusion type flames. For lowering the residence time, the high reaction rate of hydrogen is utilized by the combustion principle. Through this, it is possible to separate the reaction zone into multidiffusion type flamelets instead of several large flames. The combustor design provides, therefore, as many injection points as possible across the entire main flow area $[1,2,7]$. Additional a further miniaturization of the flames is 
achieved by the application of miniaturized injection holes, which also positively influences the mixing procedure of the reactants. The low NOx emissions are the result of multiple miniaturized $\mathrm{H}_{2}$-flamelets which lead to an optimized mixing between the reactants and low residence time in hot flame regions due to the short length of the flamlets. The actual design of the micromix burning principle is presented in Figs. $2 a$ and $2 b$. Every microinjection $\mathrm{H}_{2}$-hole is teamed with a correspondent air guiding panel gate. So, every combination of gate and injection hole is an independent jet in cross-flow process. Consequently, it is possible to scale the combustion principle to the requested thermal energy amount and to the energy density of the combustion chamber.

The geometric key parameters of the micromix burning principle are investigated in numerical and experimental prototype burner studies [8]. From this follows that besides the jet in cross-flow process, other flow phenomena have an important influence on flame stabilization and, consequently, on the resultant NOx formation, such as the wake formation of the recirculation zones, resultant from the burner geometry, impacts highly the positioning of the microflames.

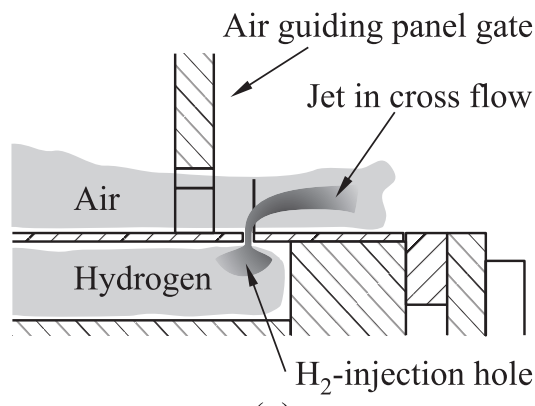

(a)

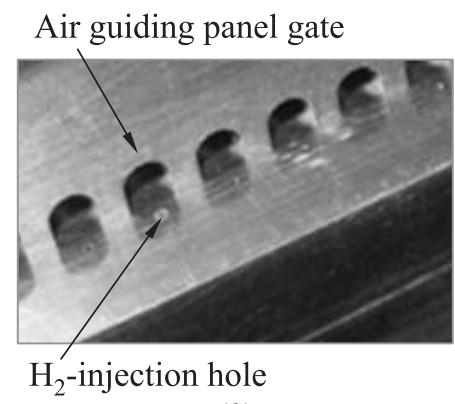

(b)

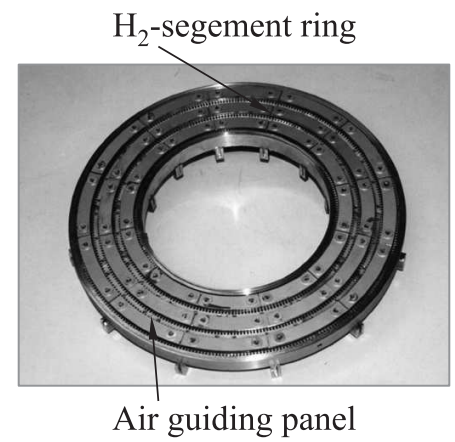

(c)

Figure 2 Micromix burning principle 
The further improvement of the combustion principle with regard to scalability and enhancement of the energy density is still part of the current research activities [9].

Figure $2 c$ shows the latest manufactured combustion chamber, based on the micromix principle, for the integration into the APU GTCP 36-300. The combustion chamber has a thermal loading power of 1.6 MW at the design point and counts 1600 microflamelets. The micromix combustion chamber consists of two main parts. The spoke centered hydrogen segment rings including the $\mathrm{H}_{2}$ injection holes, which are distributed equally on the perimeter of the rings, and the air guiding panels.

\section{GAS TURBINE MODIFICATION FOR HYDROGEN OPERATION}

The operation of an original kerosene-driven gas turbine on hydrogen requires, in addition to adaption of the control software, also several hardware modifications.

\subsection{Hardware Modifications for Hydrogen Application}

In kerosene operation, the kerosene serves also as hydraulic medium for the Inlet Guide Vane actuator of the additional load compressor. An external hydraulic unit takes over this function in hydrogen operation. The adaptation of the combustion chamber technology for the low NOx hydrogen combustion is done in several steps. In order to get familiar with the general operation character of the hydrogen-driven gas turbine, the kerosene nozzles are replaced for hydrogen nozzles. Compared to kerosene, this change does not impact significantly the formation of NOx emissions [1]. According to former fuel metering systems for gaseous hydrogen $[1,10]$, an improved hydraulic metering unit has been implemented (Fig. 3) [11].

The hydrogen is metered by a valve which is traversed by a hydraulic cylinder. The position of the cylinder defines the hydrogen mass flow and is used as control variable for the engine controller. The hydraulic Moog valve, as central part of the metering unit, determinates the amount and the speed of the cylinder operation. The valve is actuated by the engine controller. With regard to the dynamic requirements of aero engines, especially in hydrogen operation, the operational velocity is important. In addition, the gas turbine is equipped with several security valves which undertake the task of cutting automatically or manually off the hydrogen supply in case of malfunction or emergency.

For safety reasons, it is important to register the ignition of the hydrogen by detecting temperature changes. The original gas turbine Exhaust Gas Temperature (EGT) thermocouples are not able to detect these fast temperature changes. 


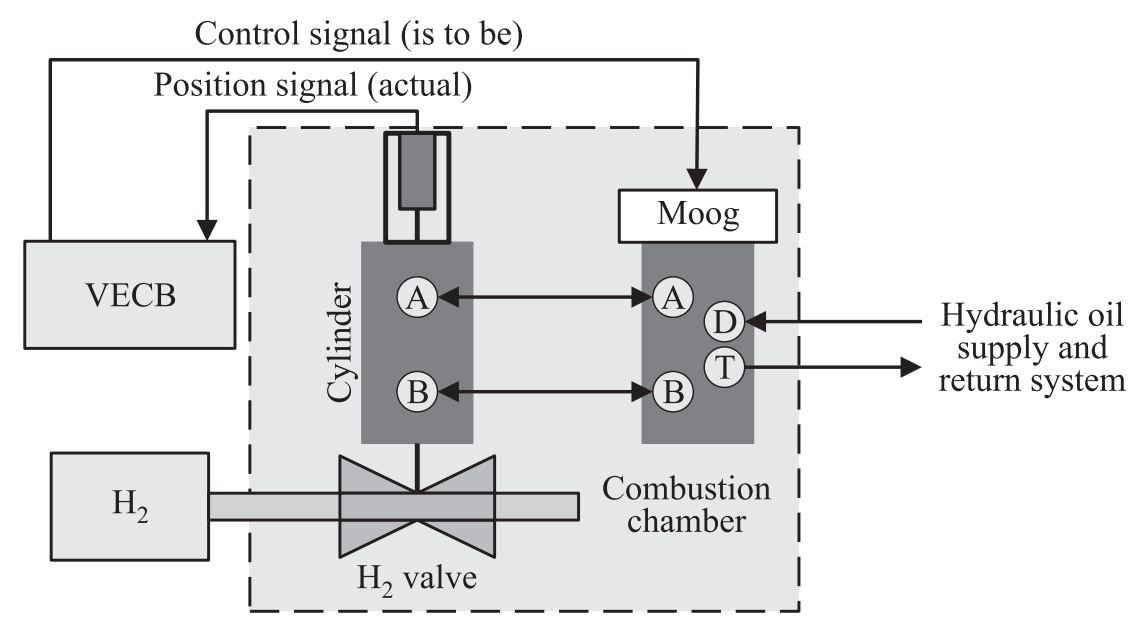

Figure 3 Hydrogen metering unit [11]

Therefore, an original thermocouple is substituted for a fast one which fulfills this function.

\subsection{Control Software Modifications}

There is one intention to use the engine's original VECB also for the hydrogen operation. This requires some modifications on the engine's control software. The implementation of an additional controller for the hydrogen metering unit represents the major software change. The VECB controls now both - the engine and the metering unit. This avoids additional and separated controller equipment for the metering unit. Every $20 \mathrm{~ms}$, the main engine controller sends the requested fuel mass flow, which equals a specific opening position of the valve, to metering unit's control loop. This controller operates the hydraulic Moog valve of the metering unit and has a clocking of $5 \mathrm{~ms}$. By operating the Moog valve, the hydraulic cylinder traverses the hydrogen valve to the requested position. The actual position of the hydrogen valve is measured by a position encoder and reported to the controller. If the actual position varies to the requested one, the control loop tries to minimize this deviation by operating the Moog valve.

Besides the integration of the metering unit's control loop, the hydrogen software is extended by some security laws. The control of the additional security valves is implemented in the hydrogen software. To prevent uncontrolled combustion during the starting sequence, the ignition process of the engine is modified. First of all, the gas turbine starts with an additional Dry Crank accelerating the engine up to $5 \%$ rotational speed to evacuate unburned hydrogen. At 
the beginning of the starting sequence, with the rotation of the gas turbine, the spark plug starts directly. When $7 \%$ rotational speed is reached, the hydrogen valve opens. To ensure the ignition of the hydrogen, the differential increase of the exhaust gas temperature in a defined window is measured by the fast thermocouple. If no ignition is detected, the hydrogen supply and the starting sequence are immediately stopped.

The main engine controller consists of two different parts. During the ignition and the starting sequence, from $0 \%$ to $95 \%$, the engine is controlled by starting sequence controller. At 95\%, the second controller, also referred to as on-speed governor, takes over. The on-speed governor controls the engine's operational behavior and keeps the APU's rotational speed constant at the requested range, autonomous from the load condition, by varying the fuel quantity. The two essential operating conditions are the ECS (Environmental Control Supply) and the MES (Main Engine Start) mode. During ECS operation, the APU delivers compressed air for the air condition. The air mass flow is metered by the variable Inlet Guide Vanes (IGV) of the load compressor. The engine's rotational speed is $99 \%$. In MES mode, the rotational speed is enhanced up to $101 \%$. The IGV open up to a defined value to provide compressed air for the starting of the main engines.

While the behavior of the on-speed governor is the same in kerosene and hydrogen operation, the start sequence controller is modified for the hydrogen operation. Based on a reference acceleration map, the kerosene controller increases or decreases the fuel mass flow for archiving the requested acceleration for each speed step. In hydrogen operation, the controller uses a function of speed for the metering of the hydrogen during the starting process. A valve opening position, and therewith a defined hydrogen mass flow, is attributed to seven decided speed steps during the acceleration of the gas turbine up to $95 \%$ rotational speed. Between two speed steps, the controller interpolates the valve's opening position.

\subsection{Setting of the Control Parameters for Operation of the Hydrogen Nozzles}

The experimental setting of the different control parameters proceeds in three steps and is based on the experiences of Ziegler and Nichols [12]. First, the PID (proportional, integral, and derivative) parameters for the hydrogen metering unit's control loop are evaluated in order to guarantee a precise metering of the requested hydrogen fuel mass flow [11].

After securing that the metering unit works in the designated conditions, the hydrogen fuel steps for the acceleration process, including the ignition, of the hydrogen-driven engine have to be adjusted. For setting the hydrogen fuel steps, several optimizations were done [13]. The kerosene mass flow during the 
acceleration process was measured and serves as reference value for the setting of the hydrogen fuel steps. There are some critical sequences, such as the offpeak starter moment and the changeover of the controller, which have to be improved for the hydrogen operation. For getting an impression on which amount the fuel steps can be decreased, a simplified performance model based on the Brayton cycle for gas turbines was prepared. The model comprehends all known engine data. The hydrogen-fueled gas turbine shows with the set fuel steps a gently acceleration from start to operation state. The critical sections during the acceleration process can be avoided by adopting the injected hydrogen amount to the simplified calculation model. The controller changeover at $95 \%$ rotational speed works without any problems.

The setting of the PID-parameters of the on-speed governor controller represents the last step. The three elements of a PID control loop allow an adjustment according to the control needs. Here, the optimizations were preceded in three steps. First, the IDLE-characteristic is tested, followed by the load operation. Thereafter, the maximum load change from IDLE-MES-IDLE is observed more in detail. The obtained results are compared to the operational behavior of the kerosene-fueled APU. The complete procedure is presented in [14]. The chosen control parameters allow a secure operation of a hydrogen-fueled APU. In face of hydrogen's compressibility and high reactivity, it is possible to operate the hydrogen-driven engine in the same way as in kerosene operation.

\section{IMPLEMENTATION OF THE LOW NOX MICROMIX COMBUSTION CHAMBER}

After successfully setting of the control parameters for the engine operation with $\mathrm{H}_{2}$-nozzles, the implementation of the micromix combustion chamber into the APU GTCP 36-300 represents the next step for the low NOx operation of a hydrogen-fueled gas turbine. Also in this case, the investigations are done in three steps. First, the control parameters for the ignition and acceleration process are adapted to the characteristic of the new low NOx combustion chamber followed by the comparison of the operational behavior of the gas turbine during operation of the micromix combustion chamber technology in reference to the $\mathrm{H}_{2}$-nozzles. The measurement of the resultant $\mathrm{NOx}$ emissions during engine operation illustrates the last step of the investigations. The control parameters for the hydrogen metering unit are kept constant.

\subsection{Setting of the Fuel Steps for Ignition and Acceleration Process}

The set fuel steps for the ignition and acceleration process are chosen with regard to the characteristic of the applied $\mathrm{H}_{2}$-nozzles. Now, when operating the gas 


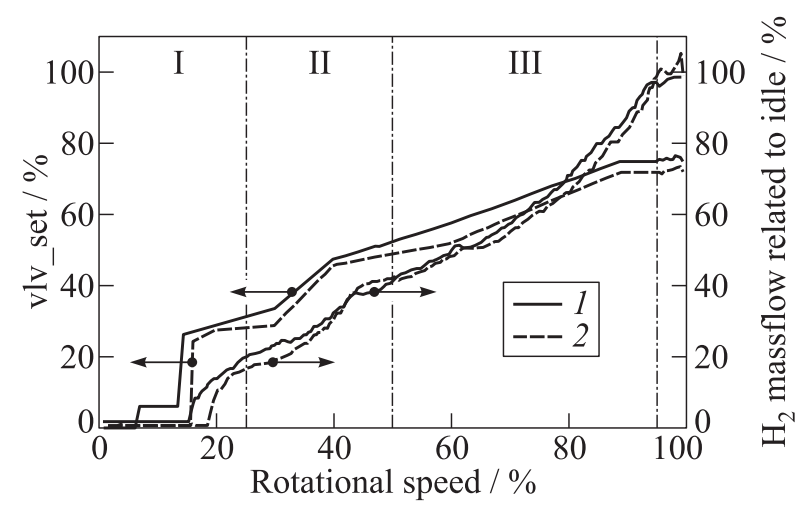

(a)

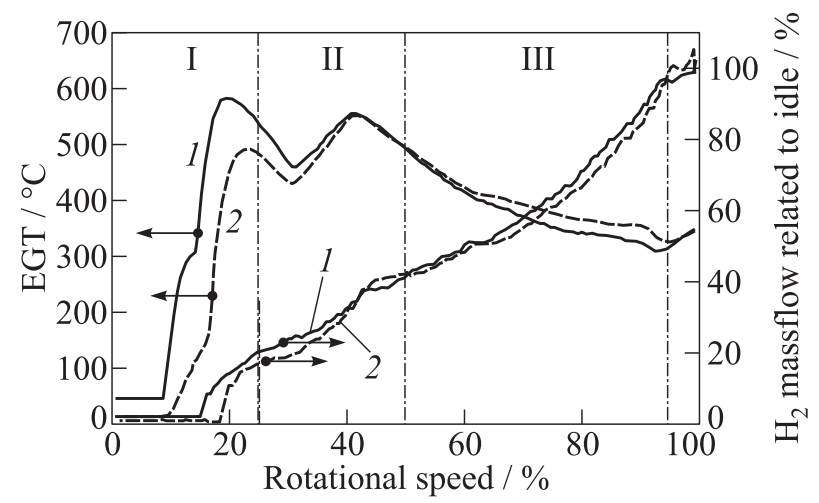

(b)

Figure 4 Ignition and acceleration process: 1 - in micromix combustion chamber; and 2 - in the nozzle

turbine with the micromix combustion chamber, they have to be adopted in order to guarantee stable and secure ignition and acceleration process. The setting of the fuel steps is discussed using Fig. 4.

Figure $4 a$ presents the set valve opening position, related to maximum opening position (vlv_set), and the resultant hydrogen mass flow, related to mass flow at IDLE operation, against rotational speed. Figure $4 b$ highlights also the hydrogen mass flow, related to mass flow at IDLE operation, and the resultant EGT against rotational speed. In addition, in Figs. $4 a$ and $4 b$, three sectors, classifying the acceleration process in three phases (I, II, and III), are plotted. These sectors are used to discuss the fuel steps setting for the different phases of the acceleration process.

The first sector (I) comprehends the ignition and the acceleration up to $25 \%$ rotational speed. This sector includes the first two fuel steps at $7 \%$ and $14 \%$ 


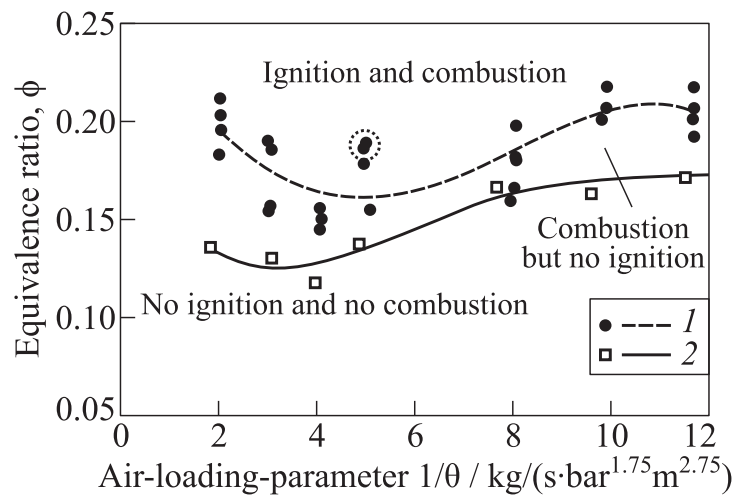

Figure 5 Ignition limits (1) and burning efficiency at $80 \%(2): T_{3}=293 \mathrm{~K}$ and $P_{3}=1$ bar

speed. For the determination of the combustion chamber's ignition point, the combustion chamber is characterized in the ACUAS's atmospheric combustion chamber laboratory. The resultant ignition points of the low NOx combustion chamber are presented in Fig. 5.

Figure 5 shows the equivalence ratio of ignition points for certain air mass flow variations against the air-loading parameter $1 / \theta$. The air-loading parameter is the reciprocal value of the $\theta$-parameter. The $\theta$-parameter is introduced by Lefebvre [15] and is the dimension for the geometric parameters and the operational conditions of the combustion chamber. In addition, Fig. 5 presents several burning efficiencies for chosen air-loading parameter. The ignition points marked by the dotted circle in Fig. 5 correlate with the prevailing conditions of the APU at $7 \%$ rotational speed. The hydrogen mass flow is transferred into a fuel valve opening position and set as the first fuel step. In comparison to $\mathrm{H}_{2}$ nozzles operation, the second fuel step has to be rearranged from $16 \%$ to $14 \%$ rotational speed. This change is necessary due to the fact that the micromix combustion chamber's EGT behavior during the ignition process is different in comparison with the $\mathrm{H}_{2}$-nozzles ones (see Fig. $4 b$ ). The combustion chamber's EGT escalates after the ignition but becomes more and more constant at a range of $300{ }^{\circ} \mathrm{C}$, while the $\mathrm{H}_{2}$-nozzles' EGT rises more linearly. As mentioned above, during the ignition process, the engine controller measures the rising of the exhaust gas temperature in a defined window. If the gradient of the temperature rise is too marginal, the controller activates the shutdown procedure. To prevent this for the micromix combustion chamber, the next fuel step after the ignition is positioned at $14 \%$ rotational speed before the resultant temperature rise's gradient is too marginal and the controller stops the starting sequence. Due to the fact that it is the aim of the investigation to start and accelerate the gas turbine without any kind of staging of the combustion chamber, a loss of burning 
efficiency is taken into account during this sequence. In consequence, compared to the $\mathrm{H}_{2}$-nozzles, more hydrogen has to be injected in order to stabilize the microflames and to accelerate the engine.

The second sector (II) includes the decreased moment of the starter and in this range, the acceleration $(d n / d t)$ reaches the smallest values during the acceleration process [13]. For compensation, more fuel has to be injected. But at lower rotational speed, the prevailing air mass flow through the gas turbine is still marginal. In consequence, a peak EGT results. In order to prevent too high temperatures, the micromix combustion chamber's fuel mass flow in this range is leant on to the $\mathrm{H}_{2}$-nozzles' fuel mass flow.

Due to the acceleration, the air mass flow through the gas turbine increases constantly in final sector (III), $50 \%$ to $95 \%$ rotational speed. This has an impor-

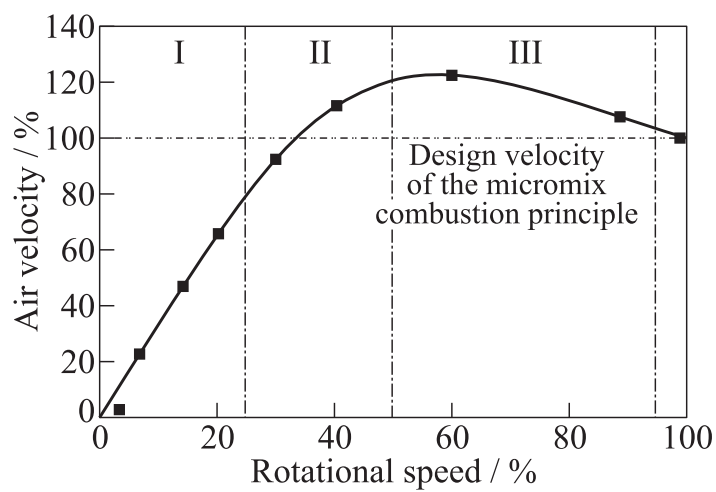

(a)

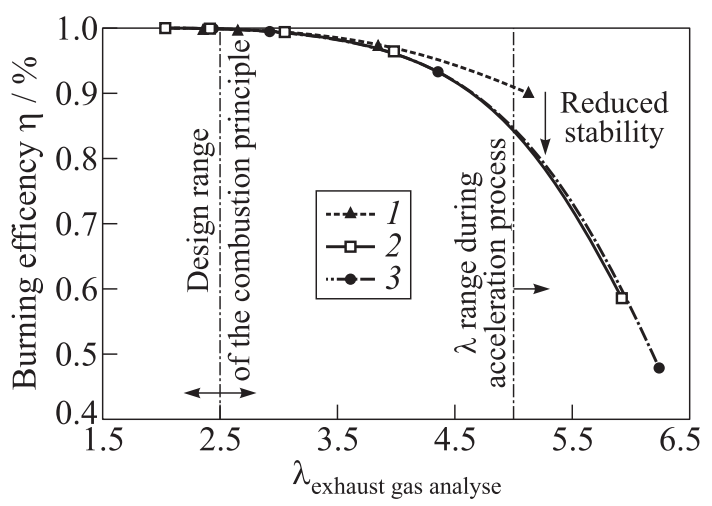

(b)

Figure 6 Air velocity $(a)$ and burning efficiency $(b): 1-110 \%$ air mass flow; $2-$ $100 \%$; and $3-75 \%$ air mass flow 
tant impact on the micromix combustion chamber's flame stabilization and on the setting of the fuel steps. Figure $6 a$ presents the velocity of the air jet through the air guiding panel gates, related to the prevailing air velocity at design point, against the APU's rotational speed. The characteristic of the air velocity during the acceleration process is caused by the variable air mass flow and density conditions, prevailing during the acceleration of the gas turbine. The maximum air velocities up to $120 \%$ of the design air velocity are reached in an area between $50 \%$ and $70 \%$ rotational speed. This increase in air velocity results in a loss of stable combustion. Figure $6 b$ demonstrates this correlation. The figure shows the impact of air mass flow variations on the burner's burning efficiency at different $\lambda$-values [9], done with a prototype test burner at the university's atmospheric combustion chamber test rig. On the vertical axis, the burning efficiency and on the horizontal axis, the $\lambda$-values are plotted. The curves represent the different tested air mass flows. The change of the air velocity is also present in the investigations (see Fig. 6b). By enhancing or lowering the air mass flow through the test burner, the air velocity is consequently increased or decreased. The acceleration process takes place at higher $\lambda$-values, while the design point of the combustion principle is set in the range of $\lambda=2.5$. In consequence and due to the fact the decision is taken to accelerate the engine without any kind of staging of the combustion chamber, a loss in burning efficiency has to be taken into account. For the acceleration of the gas turbine, more hydrogen, compared to the $\mathrm{H}_{2}$-nozzles, has to be injected in micromix combustion chamber operation.

At $95 \%$ rotational speed, the on-speed governor controller takes over and stabilizes the gas turbine at $99 \%$ rotational speed.

\subsection{Comparison of the Operational Behavior}

After the successful acceleration of the gas turbine with the fuel steps for the operation of the micromix combustion chamber, the next step is the comparison of the operational behavior in $\mathrm{H}_{2}$-nozzles and micromix combustion chamber operation. With the implementation of the micromix combustion chamber, also the manifold system for the distribution of the hydrogen to the combustion chamber's three $\mathrm{H}_{2}$-segment rings is changed and enlarged in comparison to the $\mathrm{H}_{2}$-nozzles' manifold system. In consequence, the potential risk of compressibility effects is more existant in combustion chamber operation. Furthermore, it has to be tested if the set PID-parameters [14] of the on-speed governor controller are able to operate the gas turbine with the micromix combustion chamber. Therefore, the behavior of three different operational conditions are tested and compared to behavior in $\mathrm{H}_{2}$-nozzles operation. The results are plotted in Fig. 7 . The different engine characteristics at IDLE operation and the maximum load change from IDLE to MES to IDLE are discussed. For each tested configuration, $\mathrm{H}_{2}$-nozzles and micromix combustion chamber, the three different operating con- 

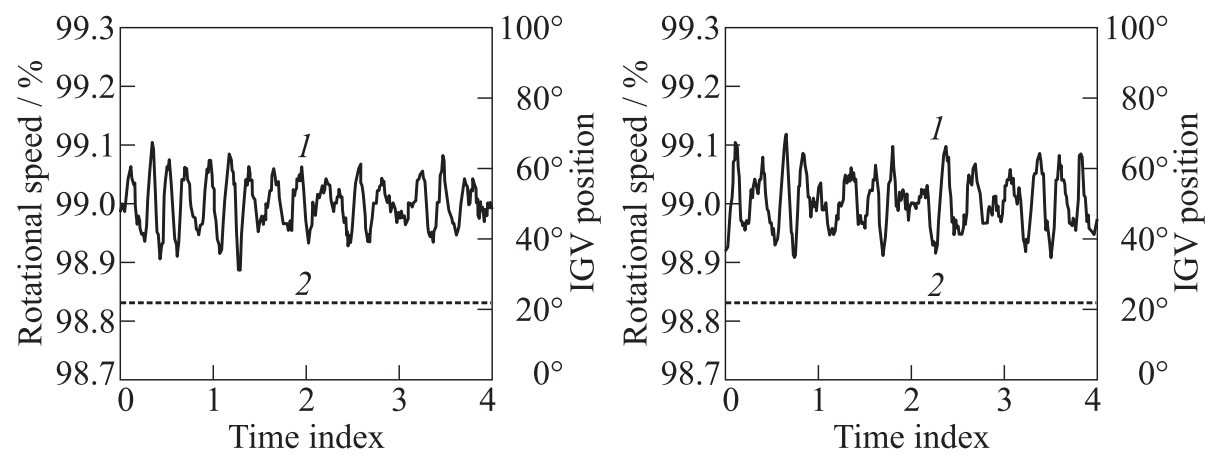

(a)
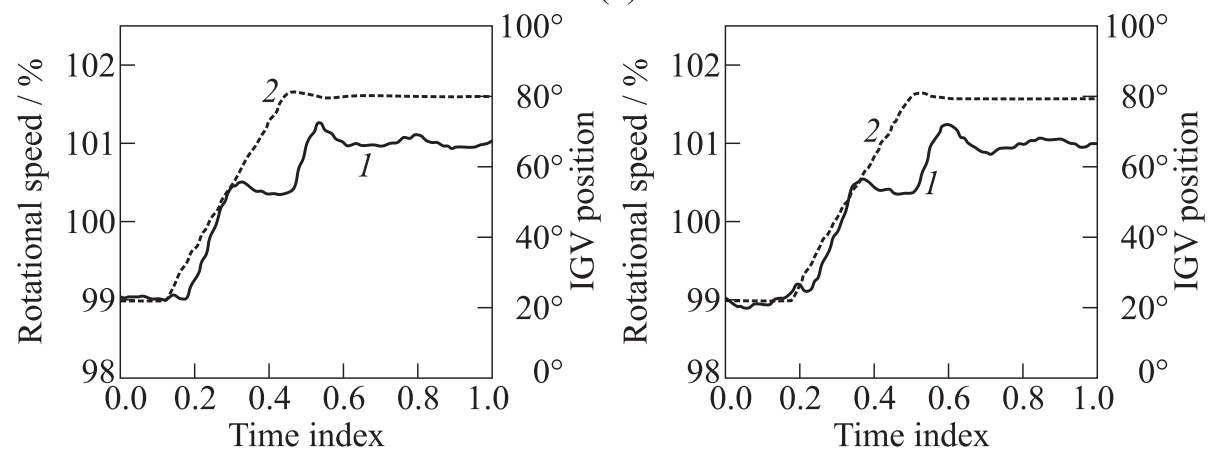

(b)
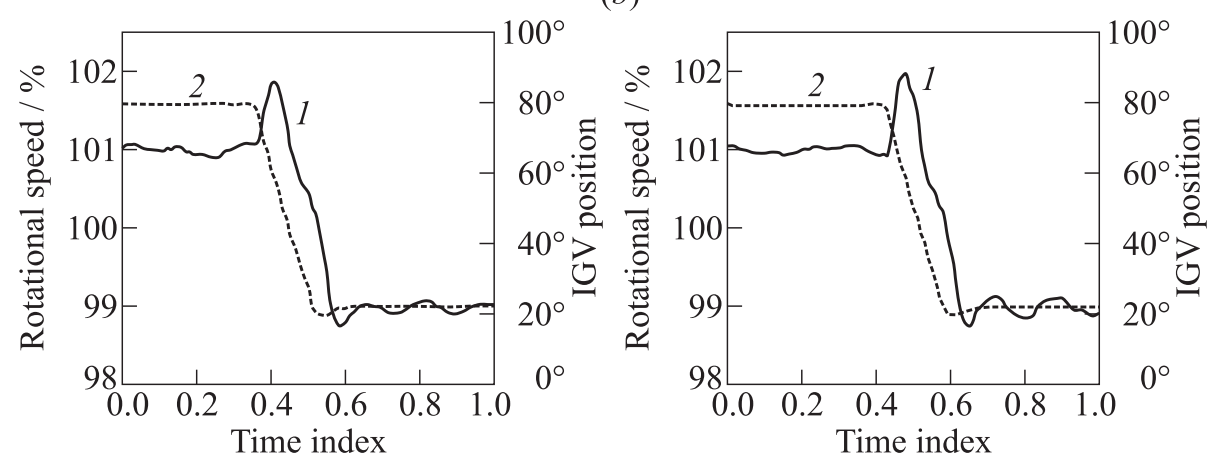

(c)

Figure 7 Operational behavior $(1-$ rotational speed, and $2-$ IGV position): (a) IDLE; (b) MES on; (c) MES off; left column $-\mathrm{H}_{2}$-nozzles operation; and right column - micromix combustion chamber operation 
ditions are presented in Fig. 7. Each diagram shows the rotational speed and the IGV position against a chosen time index. One time index equals to $20 \mathrm{~s}$.

During IDLE operation of the APU (Fig. $7 a$ ), no movement of the IGV takes place, the Load Control Valve is closed and through this, the work load of the load compressor is marginal. Therewith, the controller only has to keep the rotational speed constant at $99 \%$. The general operational behavior is quite comparable. The resultant oscillation's amplitude of the rotational speed is in the same range. The controller enables a stable IDLE operation of the gas turbine with the integrated micromix combustion chamber.

The switch form IDLE to MES (Fig. 7b) to IDLE (Fig. 7c), including the change of the speed level from $99 \%$ to $101 \%$ and back, represents the most challenging change in operational conditions. By switching from IDLE to MES, the rotational speed stabilizes in the area of $100 \%-100.5 \%$ before achieving the requested speed level of $101 \%$ in all configurations (see Fig. $7 b$ ). The stabilization is caused by load change resultant through the IGV movement [14]. Also, with the implemented combustion chamber, the controller is able to traverse rapidly, without over- or undershooting of the rotational speed to MES-mode. By switching back from MES to ILDE operation, the controller has to compensate the load compressor's decrease in load and to handle the lowering of the rotational speed. From this follows that initially the speed level overshoots and in the final stages undershoots before stabilization at $99 \%$ speed level takes place. Finally, in both cases, the controller stabilizes rapidly the rotational speed at $99 \%$. In summary, also with the implemented micromix combustion chamber, the general operation behavior of the hydrogen-fueled APU is in the desired range. Compressibility effects of the gaseous hydrogen are compensated. The set of PID-parameters of the on-speed governor allow a safe and secure operation of the hydrogen gas turbine over the whole operating range.

\subsection{NOx Emissions During Engine Operation}

For evaluating the NOx reduction potential of the micromix burning principle, the resultant NOx emissions are measured during engine operation. Therefore, the exhaust gases of the APU are measured using an isokinetic probe in order to get an equable distribution over the whole outlet section. By moving the load compressor's IGV, the APU power output can be varied. Figure 8 presents the measured NOx emissions against APU power output. For comparison, the figure also contains the resultant NOx emissions when operating the engine with the $\mathrm{H}_{2}$ nozzles and with kerosene. The hydrogen gas turbine with the low NOx micromix combustion principle shows very low dry NOx emissions over the whole operating range of the gas turbine, compared to $\mathrm{H}_{2}$-nozzles and kerosene operation. The figure points out the need of modification of the applied combustor technique for the hydrogen operation. The obtained $\mathrm{NOx}$ values in $\mathrm{H}_{2}$-nozzles operation 
are significant higher than in micromix operation, also higher than in kerosene operation. The combustion process of the $\mathrm{H}_{2}$-nozzles only takes place in six large flames. In consequence, the residence time of the reactants is significantly enlarged compared to the residence time of the micromix flamelets. Due to utilized flame miniaturization and multiplication of the micromix principle, a significant lowering of the residence time of the reactants in hot flame regions at comparable gas turbine operational conditions is achieved.

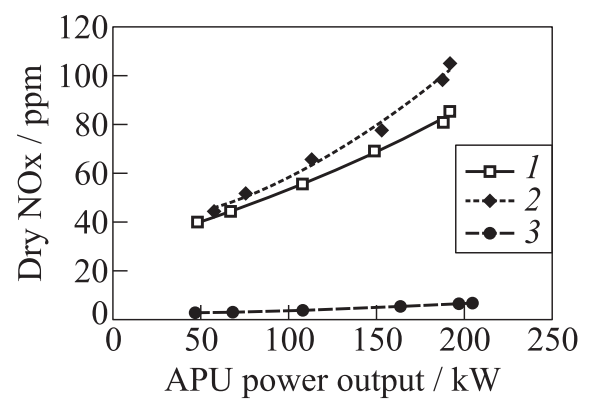

Figure 8 The NOx emissions against APU power output: $1-$ kerosene; $2-\mathrm{H}_{2}$ nozzels; and $3-\mathrm{H}_{2}$ micromix combustion chambers

\section{CONCLUDING REMARKS AND FUTURE WORK}

The implemented micromix combustion chamber and the realized hardware and software modifications allow the secure and low NOx hydrogen operation of an industrial APU. It is possible to operate the hydrogen-driven engine in the same way as in kerosene operation. The design philosophy of the micromix burning principle to use multiple small diffusion type flamelets achieves a significant reduction of the residence time and the mixture of the reactants is increased. In consequence, low NOx emissions result.

The future work objectives comprehend the deeper analyzing of the combustion principle's main geometric influencing parameters and their influence on NOx formation. In addition, the investigations of a further up scaling to higher energy densities with regard to industrial gas turbine applications are of major interest. Besides optimization of the combustion principle's resultant NOx emissions, the combustion chamber design and manufacturing will be further optimized. Manufacturing complexity and costs will be reduced while the aspect of scalability of the design concept will be extended.

\section{REFERENCES}

1. Dahl, G., and F. Suttrop. 1998. Engine control and low-NOx combustion for hydrogen fueled aircraft gas turbines. Int. J. Hydrogen Energy 23:695-704. 
2. Suttrop, F., and R. Dorneiski. 1991. Low NOx-potential of hydrogen-fueled gas turbine engines. 1st Conference (International) on Combust. Techn. for Clean Environment.

3. Goswami, M., E. N. Volkov, A. A. Konnov, R. J. M. Bastiaans, and L. P. H. de Goey. 2010. Updated kinetic mechanism for NOx prediction and hydrogen combustion. In: Low emission gas turbine technology for hydrogen-rich syngas. European Union, Contract No. FP7-Energy-2008-Tren-1, Milestone-Report M2.2. University of Technology Eindhoven, The Netherlands.

4. Lefebvre, A.H. 1984. Fuel effects on gas turbine combustion-liner temperature, pattern factor, and pollutant emissions. AIAA J. Aircraft 21:887-98.

5. Ziemann, J., F. Shum, M. Moore, D. Kluyskens, D. Thomaier, N. Zarzalis, and H. Eberius. 1998. Low-NOx combustors for hydrogen fueled aero engine. Int. J. Hydrogen Energy 23(4):281-88.

6. Heywood, J. B., and T. Mikus. 1973. Parameters controlling nitric oxide emissions from gas turbine combustion. AGARD-Technical Report No. AGARD-CPP-125. North Atlantic Treaty Organization.

7. Funke, H.H.-W., S. Boerner, A. Robinson, P. Hendrick, and E. Recker. 2010. Low $\mathrm{NOx} \mathrm{H}_{2}$ combustion for industrial gas turbines of various power ranges. 5th Conference (International) the Future of Gas Turbine Technology Proceedings. ETN2010-42.

8. Recker, E., P. Hendrick, S. Boerner, and H. H.-W. Funke. 2009. Flow and application to the "Micromix" hydrogen combustion. 19th Symposium (International) on Airbreathing Engines (ISABE). ISABE-2009-1309.

9. Funke, H., S. Boerner, W. Krebs, and E. Wolf. 2011. Experimental characterization of low NOx micromix prototype combustors for industrial gas turbine applications. ASME Turbo Expo 2011 Proceedings. GT2011-45305.

10. Dahl, G., and R. Elsing. 1992. Modification of the fuel system of a turboshaft engine from kerosene to hydrogen. 9th World Hydrogen Energy Conference Proceedings.

11. Boerner, S., H. H.-W. Funke, E. Recker, and P. Hendrick. 2009. Modification and testing of an engine and fuel control system for a hydrogen fueled gas turbine. 3rd European Conference for Aero-Space Sciences Proceedings. EUCASS-2009-198.

12. Ziegler, J. G., and N. B. Nichols. 1942. Optimum settings for automatic controllers. Trans. ASME 64:759-68.

13. Boerner, S., H.H.-W. Funke, E. Recker, and P. Hendrick. 2010.Control system modifications for a hydrogen fueled gas turbine. 13th Symposium (International) on Transport Phenomena and Dynamics of Rotating Machinery (ISROMAC) Proceedings. ISROMAC-2010-54.

14. Boerner, S., H. H.-W. Funke, F. Falk, and P. Hendrick. 2011. Control system modifications and their effects on the operation of a hydrogen-fueled Auxiliary Power Unit. 20th Symposium (International) on Airbreathing Engines (ISABE) Proceedings. ISABE-2011-1326.

15. Lefebvre, A. H. 1998. Gas turbine combustion. 2nd ed. Taylor \& Francis. 